\title{
Aggressiveness of Phytophthora cactorum, P. citricola I, and P. plurivora from European Beech
}

Jerry E. Weiland, United States Department of Agriculture-Agriculture Research Service, Horticultural Crops Research Laboratory, and Oregon State University, Department of Botany and Plant Pathology, Corvallis 97331; and Angela H. Nelson and George W. Hudler, Department of Plant Pathology and Plant-Microbe Biology, Cornell University, Ithaca, NY 14850

\begin{abstract}
Weiland, J. E., Nelson, A. H., and Hudler, G. W. 2010. Aggressiveness of Phytophthora cactorum, $P$. citricola I, and P. plurivora from European beech. Plant Dis. 94:1009-1014.

Phytophthora cactorum, P. citricola I, and P. plurivora cause bleeding cankers on mature European beech (Fagus sylvatica) trees in the northeastern United States. Inoculation experiments were conducted to compare the aggressiveness of the three Phytophthora spp. on stems, leaf disks, and roots of European beech and common lilac (Syringa vulgaris) seedlings. Isolates were obtained from bleeding cankers on European beech from five cities in New York (Albany, Ithaca, Oyster Bay, Plainview, and Rochester) and from a bleeding canker on sugar maple in Ithaca, NY. Stems were inoculated with colonized agar plugs, leaf disks with a zoospore suspension, and roots via infested soil at three inoculum levels. All organs of inoculated beech and lilac developed disease except for lilac roots inoculated with zoospores of $P$. cactorum. Disease incidence, severity, and plant survival were dependent on isolate and were also influenced by the tissue inoculated and host. Isolates of $P$. cactorum were the least aggressive and caused less necrosis than isolates of $P$. citricola I and P. plurivora. Results emphasize the utility of stem and root inoculation for evaluation of this canker disease and underscore critical differences in species aggressiveness.
\end{abstract}

Phytophthora canker, caused by Phytophthora cactorum, $P$. citricola $\mathrm{I}$, and $P$. plurivora, is a lethal disease of mature and historically valuable European beech (Fagus sylvatica) trees in the northeastern United States $(12,13)$. Symptoms initially appear as bleeding cankers on the lower trunk and root flare of affected trees. As the cankers expand, crown symptoms can include sparse foliage, leaf chlorosis and wilting, and branch dieback. Eventually, infected trees are girdled and killed.

Until recently, scientists concerned with the incidence and management of Phytophthora cankers on beech had concluded that one of the primary pathogens in both Europe and North America was P. citricola $(11,13)$. This complex species with many plant hosts comprises at least four separate taxa, each similar to the other morphologically but differing significantly in several

Corresponding author: J. Weiland

E-mail: Jerry.Weiland@ars.usda.gov

Any opinions, findings, conclusions, or recommendations expressed in this publication are those of the author and do not necessarily reflect the view of the United States Department of Agriculture.

Accepted for publication 16 April 2010.

doi:10.1094/PDIS-94-8-1009

This article is in the public domain and not copyrightable. It may be freely reprinted with customary crediting of the source. The American Phytopathological Society, 2010. defining nucleic acid sequences $(15,18)$. Further analyses of those sequences led to a determination that these four taxa are independent species: $P$. citricola I, $P$. mengei, $P$. multivora, and $P$. plurivora $(10,12,19)$. Among these new species, $P$. citricola I and $P$. plurivora are the species most frequently associated with cankered European beech. In Europe, the predominate species affecting these trees is $P$. plurivora $(11,12)$, whereas $P$. citricola $\mathrm{I}$ is predominate in the United States (12).

Other Phytophthora spp. have also been associated with diseased European beech. In an early report (1938), Day associated $P$. cambivora, $P$. cinnamomi, and $P$. syringae with root rot of European beech (8). More recently, Jung et al. (11-13) consistently isolated $P$. plurivora, $P$. cambivora, and $P$. cactorum from infected bark tissue and from rhizosphere soil samples of declining trees in Europe. In the United States, however, cankers are primarily associated with $P$. cactorum and $P$. citricola $\mathrm{I}$, although $P$. gonapodyides and $P$. plurivora occasionally have been isolated $(7,13,23)$. P. cambivora was commonly isolated from the soil underneath symptomatic and asymptomatic European beech trees sampled in New York (6 of 14 sites) but the pathogen was only isolated once from bark tissues of 150 symptomatic trees located throughout the Northeast (16). Species such as P. kernoviae, $P$. pseudosyringae, $P$. ramorum, and $P$. syringae that also cause collar rot or bleeding cankers $(4,5,11,13,14)$ were not detected in extensive surveys of European beech in the United States (16).

Variation in the ability of the pathogens to infect and kill host tissue (aggressiveness) has been found between $P$. cactorum and $P$. citricola as well as among isolates within each species. Werres (24), for example, found that beech seedlings inoculated with $P$. cactorum (eight isolates) had less disease incidence and severity than those inoculated with a single isolate of $P$. citricola. Similarly, raspberry cultivars inoculated with two $P$. cactorum isolates exhibited less root rot (3 to $24 \%$ ) than those inoculated with a $P$. citricola isolate (90 to 100\%) (25). Other studies, however, reported little or no variation in aggressiveness between these two pathogens on cherry or chestnut $(20,22)$. Variation in aggressiveness among $P$. cactorum isolates was observed by Bhat et al. (3) in inoculated strawberry plants and excised almond stems. Similarly, $P$. citricola isolates varied in aggressiveness on walnut rootstock seedlings (2). However, a specific assessment of U.S. isolates ( $P$. cactorum, $P$. citricola, and $P$. plurivora) on European beech has not been conducted, nor has the relative aggressiveness between U.S. isolates of $P$. citricola I and $P$. plurivora isolates been assessed. Because of the recent separation of these latter two species from $P$. citricola sensu stricto, relatively little research exists that directly compares the aggressiveness of these two pathogens $(12,23)$.

Thus, in an ongoing investigation into the etiology of the disease in the United States, the variation in the ability of $P$. cactorum, $P$. citricola $\mathrm{I}$, and $P$. plurivora to cause disease of two woody hosts was evaluated. Due to difficulty in obtaining European beech planting stock and seed for inoculation studies, common lilac ( $S y$ ringa vulgaris) was also investigated as a readily available host in the study. $P$. plurivora (originally identified as $P$. inflata) has been isolated from lilac, and this host was previously used in tests for susceptibility to $P$. citricola I and $P$. plurivora $(12,13)$. Furthermore, lilac was more easily propagated and more amenable to greenhouse culture than European beech. The objective of this study was to assess the aggressiveness of $P$. cactorum, $P$. citricola $\mathrm{I}$, and $P$. plurivora on stems, leaves, and roots of European beech and common lilac. 


\section{MATERIALS AND METHODS}

Isolates. Two isolates of $P$. plurivora, three of $P$. cactorum, and four of $P$. citricola I were obtained from cankers on European beech from five cities in New York (Table 1). A third isolate of $P$. plurivora, 37-04a, was obtained from a root flare canker on sugar maple (Acer saccharum). Isolates of $P$. citricola I and $P$. plurivora were initially characterized as one of two subgroups of $P$. citricola (I and II) but were later assigned to their new taxonomic designations based on DNA sequence differences within the $\beta$-tubulin and cytochrome c oxidase I and II genes, and the internal transcribed spacer region $(12,17)$. Single-spore cultures of each isolate were used in each of the inoculation experiments.

Stem inoculation. Inocula for each isolate were grown on $20 \mathrm{ml}$ of $20 \%$ clarified V8 juice agar (CV8) (23) in an 84-mmdiameter petri plate. Plates were then incubated in the dark at $20^{\circ} \mathrm{C}$. After 5 days, 5mm-diameter inoculum plugs were cut from the culture margin and used to inoculate stems of beech and lilac seedlings.

Seed of European beech were soaked for $24 \mathrm{~h}$ in tap water and then stratified in moist sand at $4^{\circ} \mathrm{C}$ for 2 months. Germinated seed were then transplanted into individual 1-liter pots containing Cornell soilless mix (equal parts peat and vermiculite with nitrogen, phosphorous, and potassium added at the rate of $0.4 \mathrm{~kg} / \mathrm{m}^{3}$ ). Seed of lilac were sown directly onto flats containing Cornell soilless mix and then covered with a 2-mm layer of vermiculite. After 2 weeks, germinated lilac seedlings were transplanted into individual 1-liter pots containing Cornell soilless mix. Beech and lilac seedlings were then grown in a greenhouse for 1 month with an average day temperature of $23^{\circ} \mathrm{C}$ and night temperature of $14^{\circ} \mathrm{C}$.

Once the beech and lilac seedlings were approximately $15 \mathrm{~cm}$ tall, the main stem of each was inoculated $10 \mathrm{~cm}$ above the soil line by removing the fourth or fifth fully expanded leaf and placing a plug of inoculum on the resulting wound, with the mycelium side toward the stem. Inoculum was held in place with Parafilm (Pechiney Plastic Packaging, Chicago), which was removed at harvest. Control stems were inoculated with sterile CV8 agar plugs. Each of the two experiments (beech and lilac stem inoculations) were arranged according to a completely randomized design (CRD) and seedlings were maintained in the greenhouse for the remainder of the experiment. Canker incidence was recorded and canker length measured to the nearest millimeter 13 days after inoculation (beech) or 9 days after inoculation (lilac). The percentage of the stem circumference affected by necrosis (or percentage of stem girdled) was also recorded to the nearest 5\%. Each isolate-host combination (including controls) was replicated 10 times and each experiment was repeated once. Stems from a subset of each isolatehost combination and control stems within each of the two trials were plated onto PARP, a semiselective medium for pythiaceous species, to confirm the presence of the pathogen.

Leaf disk inoculation. Inocula for each isolate were grown on $20 \mathrm{ml}$ of CV8 in an 84-mm-diameter petri plate and incubated in the dark at $20^{\circ} \mathrm{C}$. After 5 days, two $15-$ mm-diameter plugs were cut from the culture margin and placed into $10 \mathrm{ml}$ of $10 \%$ sterile soil extract (SSE) water in a 60-mm-diameter glass petri plate. Plates were then incubated in the dark at room temperature (RT) for $12 \mathrm{~h}$, whereupon the water was decanted and replaced with another $10 \mathrm{ml}$ of SSE. After abundant sporangia had formed ( 24 to $48 \mathrm{~h}$ ), plates were incubated at $4^{\circ} \mathrm{C}$ for $30 \mathrm{~min}$ and then brought to RT for $30 \mathrm{~min}$ to induce zoospore release. The zoospore concentration was estimated using a hemacytometer and adjusted to 1,000 zoospores $/ \mathrm{ml}$.

Leaves of healthy European beech were collected from the campus of Cornell University, Ithaca, NY by removing the third or fourth fully expanded leaf from actively growing branches in mid-April 2007. Lilac leaves were collected by removing the third or fourth fully expanded leaf from actively growing seedlings maintained in a greenhouse at $21^{\circ} \mathrm{C}$. Leaves were packed between layers of moistened paper towel and transported to the laboratory, where they were immediately rinsed in running tap water for $5 \mathrm{~min}$ and blotted dry. In order to standardize leaf area, 15-mmdiameter leaf disks were cut from each leaf with a sterile cork borer while avoiding the main central leaf vein. Each leaf disk was placed with its abaxial side up on moistened paper towel in a 60-mm-diameter glass petri plate. Leaf disks were then subjected to a wounding treatment or left nonwounded to determine whether wounding affected disease severity. For the wounding treatment, five light scratches (to score the cuticle and epidermis but not break the adaxial surface of the leaf) approximately $5 \mathrm{~mm}$ long were made in the center of each leaf disk. Then, $50 \mu \mathrm{l}$ of a 1,000-zoospore $/ \mathrm{ml}$ suspension were added directly on top of the scratched area for each isolate-host combination. Nonwounded leaves received $50 \mu \mathrm{l}$ of the spore suspension in the center of the leaf disk and control leaf disks received $50 \mu \mathrm{l}$ of sterile water. After inoculation, each petri plate was sealed with Parafilm. Each experiment was arranged according to a CRD for each host species and incubated in the dark at RT. Leaves were evaluated 5 days later for the presence or absence of necrosis (disease incidence) and the percentage of the leaf disk occupied by necrosis was rated on a 0 -to- 4 scale $(0=$ no necrosis and $1=1$ to $25,2=26$ to $50,3=51$ to 75 , and $4=76$ to $100 \%$ necrosis). Each isolatehost combination (including controls) was replicated 10 times and each experiment was repeated once. Three leaf disks from each isolate-host combination and control leaf disks within each of the two trials were plated onto PARP to confirm the presence of the pathogen.

Table 1. Canker length and girdle of European beech and common lilac seedling stems inoculated with isolates of Phytophthora cactorum, P. citricola I, and P. plurivora ${ }^{\mathrm{a}}$

\begin{tabular}{|c|c|c|c|c|c|c|c|c|c|}
\hline \multirow[b]{2}{*}{ Species, isolate } & \multirow[b]{2}{*}{ City } & \multicolumn{4}{|c|}{ Beech } & \multicolumn{4}{|c|}{ Lilac } \\
\hline & & Length (mm) & SE & Girdle (\%) & SE & Length (mm) & SE & Girdle (\%) & SE \\
\hline \multicolumn{10}{|l|}{ P. cactorum } \\
\hline $03-04 a$ & Rochester & 18 & 2.1 & 96 & 2.3 & 9 & 1.0 & 40 & 3.4 \\
\hline $26-05 a$ & Oyster Bay & 25 & 1.8 & 100 & 0.5 & 16 & 2.4 & 54 & 5.7 \\
\hline $08-04 a$ & Ithaca & 26 & 2.4 & 100 & 0.0 & 11 & 1.4 & 50 & 4.2 \\
\hline \multicolumn{10}{|l|}{ P. citricola I } \\
\hline $09-04 \mathrm{a}$ & Ithaca & 44 & 4.1 & 100 & 0.0 & 20 & 3.1 & 73 & 6.5 \\
\hline $04-05 a$ & Oyster Bay & 58 & 6.0 & 100 & 0.0 & 44 & 3.3 & 93 & 3.7 \\
\hline $06-04 a$ & Albany & 67 & 6.7 & 100 & 0.0 & 46 & 3.5 & 96 & 2.9 \\
\hline $02-04 a$ & Rochester & 71 & 7.3 & 100 & 0.0 & 43 & 3.5 & 93 & 3.6 \\
\hline \multicolumn{10}{|l|}{ P. plurivora } \\
\hline $01-02 \mathrm{a}$ & Oyster Bay & 41 & 4.1 & 100 & 0.0 & 36 & 3.3 & 90 & 4.6 \\
\hline $37-04 a$ & Ithaca & 53 & 7.5 & 100 & 0.0 & 44 & 2.8 & 99 & 1.0 \\
\hline $17-06 a$ & Plainview & 64 & 6.6 & 100 & 0.0 & 48 & 2.9 & 99 & 1.5 \\
\hline
\end{tabular}

\footnotetext{
${ }^{a}$ Inoculum was applied as a 5-mm-diameter colonized agar plug $(n=20)$. All isolates obtained from European beech except 37-04a, which was from sugar
} maple. $\mathrm{SE}=$ standard error. 
Root inoculation. Inocula for each isolate were grown on $20 \mathrm{ml}$ of CV8 in an 84mm-diameter petri plate and incubated in the dark at $20^{\circ} \mathrm{C}$. After 5 days, five $5-\mathrm{mm}-$ diameter inoculum plugs were cut from the culture margin and transferred aseptically to individual 250-ml Erlenmeyer flasks containing $20 \mathrm{~g}$ of long-grain brown rice and $17.5 \mathrm{ml}$ of clarified V8 juice broth. Each flask of rice inoculum was initially autoclaved twice at $121^{\circ} \mathrm{C}$ for $15 \mathrm{~min}$ and allowed to cool to $20^{\circ} \mathrm{C}$ before each isolate was added. Inocula were then incubated for 14 days at $20^{\circ} \mathrm{C}$ in the dark. Cultures were shaken every other day to prevent clumping.

Seed of European beech were stratified as described above and then planted into individual 266-ml cups (cup RK9; Fabri-Kal, Kalamazoo, MI) containing Cornell soilless mix. Seed of lilac were prepared as described above and seedlings were then transplanted into individual $89-\mathrm{ml}$ plastic cups (cup RK3; Fabri-Kal) containing Cornell soilless mix. Seedlings of both hosts were inoculated when all seedlings had at least one pair of true leaves. Seedlings were inoculated at one of three inoculum levels (1,3, or 5 infested rice grains per $100 \mathrm{ml}$ of soil) for each of the 10 isolates by pushing infested grains to $1 \mathrm{~cm}$ below the soil line with sterile forceps. Control cups received 1,3 , or 5 sterile rice grains per $100 \mathrm{ml}$ of soil. The experiment was arranged in a CRD for each host species. At 2 weeks after transplanting, and every 2 weeks thereafter, each cup was flooded for $48 \mathrm{~h}$ with distilled water (6). The water surface was maintained approximately $0.5 \mathrm{~cm}$ above the soil surface. After 2 days, the cups were allowed to dry and were kept at field capacity until the next flooding event. Disease incidence and the number of weeks each seedling remained alive (seedling survival) were recorded weekly until each experiment was terminated at 14 weeks after inoculation. Each isolate-host combination (including controls) was replicated 5 times (beech) or 10 times (lilac) and each experiment was repeated once. A subset of seedlings from each isolate and inoculum level were assayed for the presence of the pathogen by plating onto PARP.

Statistical analyses. Disease incidence data for each host and inoculation treatment (stem, leaf disk, or root inoculation) were analyzed by the $\chi^{2}$ test of independence for effects of isolate and trial. Severity data from stems (canker length and girdle) were analyzed by two-way analysis of variance (ANOVA) for effects of isolate, trial, and interaction. Girdle data were converted into proportions (percentage of stem circumference affected by necrosis/100) and transformed by the arcsine of the square root to homogenize variance before analyses. Ratings of leaf disk necrosis and survival data from the root inoculation experiment were analyzed for effects of isolate and trial with the nonparametric Kruskal-Wallis test. If trial effects were observed, data from each trial were also analyzed separately. Relationships among incidence, severity, and plant survival between hosts were examined by calculating Pearson correlation coefficients. Analyses were performed with Minitab Statistical Software (release 15.1; Minitab Inc., State College, PA).

\section{RESULTS}

Stem inoculation. All inoculated stems of beech and lilac developed a canker in response to inoculation. Cankers were visible within the first week after inoculation and appeared as dark, sunken depressions on the stem. Bleeding was observed on less than $5 \%$ of the stems and did not appear consistently enough to determine whether the symptom was dependent on either isolate or host. Control stems never developed cankers.

Canker length ranged from $18 \mathrm{~mm}$ (isolate $03-04 a$ ) to $71 \mathrm{~mm}$ (isolate $02-04 \mathrm{a}$ ) on beech and from $9 \mathrm{~mm}$ (isolate 03-04a) to $48 \mathrm{~mm}$ (isolate 17-06a) on lilac (Table 1). Cankers caused by $P$. cactorum isolates on either host were always shorter than those caused by isolates of $P$. citricola I and $P$. plurivora $(P<0.001)$. ANOVAs indicated an effect of isolate on canker length for both beech $(P<0.001)$ and lilac $(P<$ $0.001)$. No effect of trial or trial-isolate interaction was detected for either host $(P$ $\geq 0.161$ ). Therefore, pooled data are presented. Canker length of inoculated beech was strongly correlated with that of lilac $(r$ $=0.925, P<0.001)$, with isolates maintaining a similar level of aggressiveness regardless of host.

Table 2. Disease incidence and severity ratings of European beech and common lilac leaf disks inoculated with isolates of Phytophthora cactorum, P. citricola $\mathrm{I}$, and $P$. plurivora ${ }^{\mathrm{a}}$

\begin{tabular}{|c|c|c|c|c|c|c|c|}
\hline \multirow[b]{2}{*}{ Host, species } & \multirow[b]{2}{*}{ Isolate } & \multicolumn{2}{|c|}{ Disease incidence $(\%)^{\mathbf{b}}$} & \multicolumn{4}{|c|}{ Disease severity rating ${ }^{\mathrm{c}}$} \\
\hline & & Nonwounded & Wounded & Nonwounded & SE & Wounded & SE \\
\hline \multicolumn{8}{|l|}{ Beech } \\
\hline \multirow[t]{3}{*}{ P. cactorum } & $03-04 a$ & 100 & 100 & 2.4 & 0.20 & 2.8 & 0.25 \\
\hline & $26-05 a$ & 90 & 95 & 1.8 & 0.29 & 2.4 & 0.34 \\
\hline & $08-04 a$ & 80 & 100 & 1.6 & 0.28 & 1.6 & 0.20 \\
\hline \multirow[t]{4}{*}{ P. citricola $\mathrm{I}$} & 09-04a & 45 & 85 & 0.6 & 0.21 & 1.0 & 0.11 \\
\hline & $04-05 a$ & 90 & 95 & 2.5 & 0.34 & 3.0 & 0.26 \\
\hline & $06-04 a$ & 95 & 100 & 2.9 & 0.32 & 4.0 & 0.05 \\
\hline & $02-04 a$ & 80 & 95 & 3.1 & 0.36 & 3.5 & 0.26 \\
\hline \multirow[t]{3}{*}{ P. plurivora } & $01-02 \mathrm{a}$ & 95 & 95 & 1.2 & 0.11 & 1.5 & 0.17 \\
\hline & $37-04 a$ & 85 & 95 & 1.7 & 0.29 & 2.1 & 0.31 \\
\hline & $17-06 a$ & 90 & 85 & 1.4 & 0.20 & 1.8 & 0.27 \\
\hline \multicolumn{8}{|l|}{ Lilac } \\
\hline \multirow{3}{*}{ P. cactorum } & $03-04 a$ & 0 & 25 & 0.0 & 0.00 & 0.5 & 0.22 \\
\hline & $26-05 a$ & 25 & 100 & 1.0 & 0.40 & 4.0 & 0.05 \\
\hline & $08-04 a$ & 0 & 30 & 0.0 & 0.00 & 0.9 & 0.34 \\
\hline \multirow[t]{4}{*}{ P. citricola $\mathrm{I}$} & $09-04 a$ & 30 & 70 & 0.6 & 0.23 & 1.8 & 0.35 \\
\hline & $04-05 a$ & 100 & 95 & 4.0 & 0.00 & 3.8 & 0.20 \\
\hline & $06-04 a$ & 55 & 95 & 2.1 & 0.45 & 3.8 & 0.20 \\
\hline & $02-04 a$ & 80 & 95 & 3.2 & 0.37 & 3.8 & 0.20 \\
\hline \multirow[t]{3}{*}{ P. plurivora } & $01-02 \mathrm{a}$ & 75 & 100 & 3.0 & 0.39 & 4.0 & 0.00 \\
\hline & $37-04 a$ & 45 & 100 & 1.8 & 0.46 & 4.0 & 0.00 \\
\hline & $17-06 a$ & 60 & 100 & 2.4 & 0.45 & 4.0 & 0.00 \\
\hline
\end{tabular}

${ }^{a}$ Inoculum was applied as $50 \mu \mathrm{l}$ of 1,000 zoospores $/ \mathrm{ml}$ on nonwounded or wounded leaf disks $(n=$ 20). $\mathrm{SE}=$ standard error.

${ }^{\mathrm{b}}$ Disease incidence recorded as the percentage of leaf disks with necrosis 5 days after inoculation.

${ }^{\mathrm{c}}$ Disease severity rated on a 0 -to- 4 scale $(0=$ no necrosis and $1=1$ to $25,2=26$ to $50,3=51$ to 75 ,
The percentage of the stem circumference affected by necrosis ranged from $96 \%$ (isolate $03-04 a)$ to $100 \%$ (remaining isolates) on beech and from $42 \%$ (isolate 03 to $99 \%$ (isolates $37-04 a$ and $17-06 a$ ) always girdled less than those inoculated with isolates of $P$. citricola I or $P$. ivora $(P<0.001)$. However, on beech, amount of stem tisue girdled between $P$. cactorum isolates 08-04a and 26-05a and $P$. citricola $\mathrm{I}$ and $P$. plurivora isolates $(P=$ $0.174)$. Only $P$. cactorum isolate $03-04$ a ess stem tissue than any $P$. citricola I or $P$. plurivora isolate $(P=0.004)$. ANOVAs indicated an effect of isolate on but not of trial or trial-isolate interaction $(P \geq 0.081)$. Therefore, pooled data are presented. The percentage of the stem girdled in beech by each of the isolates urements in lilac $(r=0.600, P=0.067)$.

Leaf disk inoculation. Necrosis was visible on leaf disks within 2 days after inoculation and appeared as dark-brown to werions. Droplets of reddish-brown fluid were frequently observed the surface of necrotic leaf tissue but isolate or host. Control leaf disks never developed necrosis.

Disease incidence ranged from 45 to $100 \%$ (nonwounded) and 85 to $100 \%$ (wounded) in beech leaf disks and 0 to $100 \%$ (nonwounded) and 25 to $100 \%$ lated with isolates of $P$. cactorum were 作

and $4=76$ to $100 \%$ necrosis).

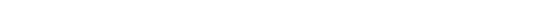


(wounded) in lilac leaf disks (Table 2). Inoculation of lilac leaf disks with $P$. cactorum isolates resulted in less disease incidence than with isolates of $P$. citricola $\mathrm{I}$ or $P$. plurivora $(P<0.001)$. This difference was not observed in beech $(P=0.147)$. Disease incidence of nonwounded beech leaf disks was dependent on isolate $(P<$ 0.001 ) but was independent of isolate for wounded leaf disks $(P=0.503)$. However, when incidence data from isolate 09-04a (with the least incidence of necrosis, $45 \%$ ) was removed from the nonwounded data set, the disease incidence of the remaining nine isolates was independent of isolate $(P$ $=0.445)$. In contrast, disease incidence was always dependent on isolate for both nonwounded and wounded lilac leaf disks $(P<0.001)$. Wounding usually resulted in greater disease incidence in beech leaf disks but was only significant for isolates 08-04a and 09-04a $(P \leq 0.035)$. In contrast, an effect of wounding was observed for 8 of 10 isolates in lilac $(P \leq 0.035)$ but not for isolates $02-04 \mathrm{a}$ and $04-05 \mathrm{a}(P \geq 0.151)$. Effects of trial were observed in 5 of 40 isolate-wound treatment combinations $(P<$ 0.050). However, results were similar when data from the two trials were analyzed separately. Therefore, pooled data are presented. Disease incidence of nonwounded and wounded beech leaf disks was not correlated with that of lilac $(P \geq 0.290)$.

Disease severity ratings ranged from 0.6 to 3.1 (nonwounded) and 1.0 to 4.0 (wounded) in beech leaf disks and 0.0 to 4.0 (nonwounded) and 0.5 to 4.0 (wounded) in lilac leaf disks (Table 2). Inoculation of lilac leaf disks with $P$. cac- torum isolates usually resulted in less disease severity than inoculation with isolates of $P$. citricola I or $P$. plurivora $(P<0.001)$. In beech, disease severity was greatest for inoculation with isolates of $P$. citricola $\mathrm{I}$, intermediate with isolates of $P$. cactorum, and least with isolates of $P$. plurivora $(P<$ $0.001)$. Disease severity ratings of both beech and lilac leaf disks were dependent on isolate $(P \leq 0.001)$ for both wounded and nonwounded treatments. Wounding usually resulted in greater disease severity in beech leaf disks but was only significant for isolates 06-04a and 09-04a $(P \leq 0.014)$. In contrast, an effect of wounding was observed for 8 of 10 isolates in lilac $(P \leq$ 0.019 ) but not for isolates 02-04a and 0405a $(P \geq 0.157)$. An effect of trial was observed in 12 of 40 isolate-wound treatment combinations $(P<0.050)$. However, results were similar when data from the two trials for each host were analyzed separately. Therefore, pooled data are presented. Disease severity ratings from nonwounded or wounded beech leaf disks were not correlated with those of lilac $(P \geq$ 0.302).

Root inoculation. Leaves of affected seedlings began to wilt within 1 week after inoculation. Leaves were occasionally chlorotic in the week or two prior to wilting but no effects of isolate or host were observed. Once wilt symptoms appeared, most seedlings died within 2 weeks. Roots developed numerous tan lesions which eventually coalesced and spread into the seedling crown. Control seedlings never developed chlorosis, wilting, or necrosis and survived for the duration of the study.
Disease incidence ranged from 30 to $90 \%$ in beech and 0 to $75 \%$ in lilac at inoculum level 1 (1 infested rice grain per $100 \mathrm{ml}$ of soil; Table 3). Similar ranges in disease incidence were observed at the other two inoculum levels ( 3 and 5 infested rice grains per $100 \mathrm{ml}$ of soil, respectively). Inoculation of either beech or lilac with isolates of $P$. cactorum always resulted in less disease incidence than with isolates of $P$. citricola $\mathrm{I}$ or $P$. plurivora $(P \leq$ $0.001)$. In addition, disease incidence was almost always greater on beech than on lilac, regardless of isolate or inoculum level. Disease incidence was dependent on isolate $(P \leq 0.002)$ for all inoculum levels of both hosts. Although disease incidence increased with increasing levels of inoculum for some isolates, this effect was neither consistent nor significant $(P \geq 0.075)$, except for isolate $01-02 \mathrm{a}$ on beech $(P=$ $0.044)$. An effect of trial was only found for beech inoculated with isolate 37-04a at inoculum level $1(P=0.025)$ and no interactions between isolate, trial, or treatment were observed $(P \geq 0.088)$. Results were similar when data from the two trials for each host were analyzed separately. Therefore, pooled data are presented. Disease incidence of beech was correlated to that of lilac for each of the three inoculum levels $(r \geq 0.791, P \leq 0.006)$.

Seedling survival (average number of weeks that seedlings survived) ranged from 4.7 to 12.0 weeks in beech and 9.2 to 14 weeks in lilac at inoculum level 1 (Table 3). Similar ranges of survival were observed at the other two inoculum levels. Seedlings of both hosts survived longer

Table 3. Disease incidence and seedling survival of European beech and common lilac planted in soil infested with isolates of Phytophthora cactorum, P. citricola I, and P. plurivora ${ }^{\text {a }}$

\begin{tabular}{|c|c|c|c|c|c|c|c|c|c|c|}
\hline \multirow[b]{3}{*}{ Host, species } & \multirow[b]{3}{*}{ Isolate } & \multicolumn{9}{|c|}{ Inoculum level (no. of colonized rice grains per $100 \mathrm{ml}$ of soil) ${ }^{b}$} \\
\hline & & \multicolumn{3}{|c|}{1} & \multicolumn{3}{|c|}{3} & \multicolumn{3}{|c|}{5} \\
\hline & & Inc. $(\%)$ & Survival & SE & Inc. $(\%)$ & Survival & SE & Inc. $(\%)$ & Survival & SE \\
\hline \multicolumn{11}{|l|}{ Beech } \\
\hline \multirow[t]{3}{*}{ P. cactorum } & $03-04 a$ & 30 & 11.7 & 1.30 & 50 & 11.0 & 1.56 & 40 & 10.0 & 1.68 \\
\hline & $26-05 a$ & 40 & 10.8 & 1.45 & 70 & 9.0 & 1.54 & 60 & 9.6 & 1.38 \\
\hline & $08-04 a$ & 30 & 12.0 & 1.11 & 10 & 13.4 & 0.60 & 40 & 11.6 & 1.46 \\
\hline \multirow[t]{4}{*}{ P. citricola I } & $09-04 a$ & 50 & 10.3 & 1.37 & 80 & 5.5 & 1.49 & 90 & 7.5 & 1.49 \\
\hline & $04-05 a$ & 90 & 6.0 & 1.09 & 90 & 3.9 & 1.17 & 100 & 2.5 & 0.27 \\
\hline & $06-04 a$ & 80 & 6.1 & 1.46 & 100 & 3.9 & 0.96 & 100 & 3.5 & 0.45 \\
\hline & $02-04 a$ & 90 & 5.0 & 1.03 & 100 & 4.0 & 0.60 & 90 & 4.7 & 1.39 \\
\hline \multirow{3}{*}{ P. plurivora } & $01-02 a$ & 60 & 7.7 & 1.74 & 100 & 2.9 & 0.61 & 90 & 4.3 & 1.12 \\
\hline & $37-04 a$ & 90 & 5.6 & 1.06 & 80 & 6.5 & 1.41 & 90 & 5.5 & 1.59 \\
\hline & $17-06 a$ & 90 & 4.7 & 1.11 & 100 & 3.5 & 0.56 & 100 & 3.1 & 0.48 \\
\hline \multicolumn{11}{|l|}{ Lilac } \\
\hline \multirow[t]{3}{*}{ P. cactorum } & $03-04 a$ & 0 & 14.0 & 0.00 & 0 & 14.0 & 0.00 & 0 & 14.0 & 0.00 \\
\hline & $26-05 a$ & 0 & 14.0 & 0.00 & 0 & 14.0 & 0.00 & 0 & 14.0 & 0.00 \\
\hline & $08-04 a$ & 0 & 14.0 & 0.00 & 0 & 14.0 & 0.00 & 0 & 14.0 & 0.00 \\
\hline \multirow[t]{4}{*}{ P. citricola I } & $09-04 a$ & 20 & 13.8 & 0.16 & 45 & 11.8 & 0.79 & 50 & 12.1 & 0.77 \\
\hline & 04-05a & 55 & 12.6 & 0.44 & 70 & 12.1 & 0.59 & 65 & 11.0 & 0.83 \\
\hline & $06-04 a$ & 75 & 10.4 & 0.83 & 90 & 9.8 & 0.86 & 65 & 9.9 & 0.99 \\
\hline & $02-04 a$ & 75 & 9.2 & 1.04 & 95 & 8.5 & 1.00 & 95 & 7.2 & 0.88 \\
\hline \multirow[t]{3}{*}{ P. plurivora } & $01-02 a$ & 35 & 11.6 & 0.86 & 50 & 10.7 & 1.04 & 70 & 11.0 & 0.99 \\
\hline & $37-04 a$ & 45 & 13.1 & 0.43 & 80 & 9.8 & 0.84 & 70 & 10.0 & 0.99 \\
\hline & $17-06 a$ & 75 & 11.7 & 0.74 & 70 & 11.0 & 0.86 & 65 & 10.6 & 0.84 \\
\hline
\end{tabular}

${ }^{\mathrm{a}}$ Inoculum was applied as 1, 3, or 5 infested rice kernels per $100 \mathrm{ml}$ of soil. European beech, $n=10$; lilac, $n=20$.

${ }^{\mathrm{b}}$ Inc. $(\%)=$ disease incidence recorded as the percentage of seedlings exhibiting wilting or necrosis, Survival indicates average number of weeks seedlings remained alive, and $\mathrm{SE}=$ standard error. 
when inoculated with $P$. cactorum isolates than those inoculated with isolates from either $P$. citricola $\mathrm{I}$ or $P$. plurivora $(P \leq$ 0.018 ) but this was not significant for lilac at inoculum level $1(P=0.135)$. Furthermore, lilac always survived longer than beech, regardless of isolate or inoculum level. Survival was dependent on isolate $(P$ $\leq 0.001$ ) for all inoculum levels of both hosts. Although survival decreased with increasing levels of inoculum for some isolates, this effect was neither consistent nor significant $(P \geq 0.066)$, except for isolates $01-02 \mathrm{a}$ and $04-05 \mathrm{a}$ on beech $(P \leq$ $0.023)$ and isolate $37-04 a$ on lilac $(P=$ $0.005)$. An effect of trial was found for only 3 of 60 isolate-inoculum level combinations for both hosts $(P \leq 0.026)$. Results were similar when data from the two trials were analyzed separately. Therefore, pooled data are presented. Survival of beech seedlings was correlated to that of lilac for each of the three inoculum levels $(r \geq 0.769, P \leq 0.009)$.

Comparison of inoculation treatments. Means of disease incidence and severity for each isolate were influenced by the tissues inoculated. Stem disease severity (canker length and girdle) was most frequently related to disease incidence and survival of root-inoculated plants but infrequently related to disease incidence and severity of leaf disks. For example, isolate 09-04a caused intermediate damage to beech stems and rootinoculated beech seedlings but was one of the least damaging to beech leaf disks. Isolate $03-04 \mathrm{a}$, in contrast, caused little damage to beech stems and root-inoculated beech seedlings but caused some of the greatest amounts of necrosis to beech leaf disks. Stem disease severity of beech and lilac was never correlated with beech leaf disease incidence and severity $(P \geq 0.103)$ but was occasionally correlated with that from lilac leaf disks $(r \geq 0.636, P \leq 0.048)$. However, stem disease severity of both hosts (except beech canker girdle) was positively correlated with root disease incidence $(r \geq 0.621, P \leq 0.045)$ and negatively correlated with survival of rootinoculated plants of both hosts at all three inoculum levels $(r \leq-0.632, P \leq 0.049)$. Beech leaf disk disease incidence and severity were never correlated with root disease incidence or survival or rootinoculated plants of either host. In contrast, lilac leaf disk disease incidence and severity were positively correlated with root disease incidence $(r \geq 0.660, P \leq 0.038)$ and negatively correlated with survival of root-inoculated plants of both hosts at all three inoculum levels $(r \leq-0.644, P \leq$ 0.044).

\section{DISCUSSION}

All isolates tested were pathogenic on beech and lilac, indicating that the pathogens were not host specific. However, inoculation with isolates of $P$. cactorum generally resulted in less disease incidence and severity than inoculation with either $P$. citricola I or P. plurivora regardless of the host or tissue tested. This supports the findings of earlier studies indicating that $P$. cactorum was less aggressive on European beech than $P$. citricola I (identified as $P$. citricola isolate 14-04a) in the United States (23) and P. citricola in Germany (24). It is also representative of our findings in inoculations of mature beech (J. E. Weiland, unpublished) in which two European beech and five American beech $(F$. grandifolia) trees were each inoculated with $P$. cactorum (isolate $08-04 a), P$. citricola I (isolate 06-04a), and P. plurivora (isolates 17-06 and 37-04a) in June 2007. Colonized agar plugs were placed into holes drilled into the trunk, sealed, and evaluated 3 months later. Cankers caused by $P$. citricola I averaged 380 and $250 \mathrm{~cm}^{2}$ in size on European and American beech, respectively, whereas inoculation with $P$. plurivora resulted in an average canker size of 778 and $170 \mathrm{~cm}^{2}$, respectively. Cankers caused by $P$. cactorum (08-04a) were much smaller and averaged 40 and 4 $\mathrm{cm}^{2}$ on European and American beech, respectively. Cankers did not develop on control stems inoculated with sterile agar.

All tissues of European beech were susceptible to infection by $P$. cactorum, $P$. citricola $\mathrm{I}$, and $P$. plurivora. Lilac stems, leaf disks, and roots were similarly susceptible, except that roots inoculated with the three $P$. cactorum isolates never developed disease. Despite the susceptibility of leaf tissues in our experimental treatments, we have not observed leaf symptoms indicative of Phytophthora spp. infection in surveys of affected European beech throughout the northeastern United States. Furthermore, only a single root canker was found in excavations of two mature European beech trees with numerous trunk cankers caused by $P$. citricola $\mathrm{I}$. In both cases, roots were apparently free of disease (no observable lesions) and root pieces plated on PARP never yielded Phytophthora isolates. The one exception was a 2-cm-diameter root canker found $3 \mathrm{~cm}$ from the soil surface and $15 \mathrm{~cm}$ from an active trunk canker. The canker tested positive with a Phytophthora enzymelinked immunosorbent assay test kit but no isolate was ever recovered from the tissue. In contrast, root lesions and trunk cankers caused by $P$. plurivora are readily evident on beech trees in Europe (11-13). These observations suggest that there may be a significant difference between the ability of P. citricola I and P. plurivora to infect roots of mature European beech. The results of the current study illustrate that $P$. citricola I is capable of infecting roots of beech seedlings, although it is not known how these results extrapolate to the landscape. A greater number of mature root systems need to be examined in North America in order to evaluate root damage of cankered and declining trees. Unfortunately, the high value placed on mature European beech specimens in the United States makes it unlikely that the roots of numerous trees will be examined.

Isolate aggressiveness was observed to be dependent on tissue, with similar levels of aggressiveness observed in stem and root tissues but not in leaf tissues. Other researchers have also noted differences in Phytophthora spp. aggressiveness that were tissue dependent $(1,9,21)$. Tanoak, for example, developed limited necrosis on leaves inoculated with $P$. ramorum but stems were much more susceptible and developed extensive necrosis (9). In the present study, this effect of tissue may be due, in part, to differences in inoculation methodology or inoculum type (hyphae versus zoospores). In addition, mechanisms of susceptibility or resistance may vary between stems, leaves, and roots. Another factor that may have influenced the lack of correlation between beech stems and roots to leaf tissues may have been the use of greenhouse-grown material for the stem- and root-inoculation experiments and the use of field-collected leaves in the leaf disk inoculation experiment. Although an attempt was made to collect young and succulent leaf tissues, the leaves may have been sufficiently affected by the outdoor environment and, thus, influenced the experimental outcome. Given the correlation between stem and root inoculations in the present study and the observation that these tissues are frequently infected by Phytophthora spp. in the landscape and forest, future inoculation experiments should give preference to inoculation of stems and roots over leaves.

The range in aggressiveness of the pathogens in stem- and root-inoculated lilac was similar to that of European beech. This provides some evidence that lilac seedlings may prove to be a suitable model for future inoculation studies if planting stock of European beech remains limited in the United States. However, caution should be exercised because differences in isolate aggressiveness within each species were observed on the two hosts despite correlation of results. Studies testing new Phytophthora isolates should include a small number of European beech seedlings for each isolate in order to confirm that aggressiveness continues to be similar across the two hosts.

Pathogen identification is an important consideration in continuing research on Phytophthora canker of European beech. The taxonomic confusion surrounding the $P$. citricola complex has made it difficult to conduct research on this disease and has made interpretation of related scientific literature challenging. For example, isolates of $P$. citricola I and $P$. plurivora from European beech in Europe and North America were originally identified as $P$. citricola, and less frequently as $P$. inflata 
(12). Subsequent analyses of numerous isolates across both continents have led to the current species designations and, in all likelihood, $P$. citricola I will soon receive a new species name. The predominance of $P$. plurivora on European beech in Europe and $P$. citricola $\mathrm{I}$ on European beech in the United States illustrates the necessity of pathogen identification, and additional isolates of $P$. citricola $\mathrm{I}$ and $P$. plurivora need to be evaluated in future aggressiveness and fungicide sensitivity studies. Species differences in response to fungicides have already been found with $P$. cactorum, $P$. citricola I, and $P$. plurivora isolates, which indicates the importance of identifying the causal agent before fungicides are applied to infected specimen trees (23). Specifically, $P$. cactorum was less sensitive to phosphonate but more sensitive to mefenoxam than $P$. citricola $\mathrm{I}$. The current study finds additional evidence that pathogen identity plays an important role because $P$. cactorum is less aggressive on European beech than either $P$. citricola I or $P$. plurivora. However, further studies are needed to more fully explore the differences in biology between the latter two species. As such, this research highlights the significance of pathogen identity and biology in understanding the etiology of Phytophthora canker on European beech and provides a basis for future research regarding this disease.

\section{ACKNOWLEDGMENTS}

Research reported herein was supported in part by grants from Agri-Chem Inc., Rainbow TreeCare Scientific Advancements Inc., and the Cornell University Agricultural Experiment Station Federal Formula Funds, Project No. NYC-1536413 received from the Cooperative State Research, Education and Extension Service, United States Department of Agriculture.

\section{LITERATURE CITED}

1. Balci, Y., Gottschalk, K. W., MacDonald, W. L., and Balci, S. 2008. Relative susceptibility of oaks to seven species of Phytophthora isolated from oak forest soils. For. Pathol. 38:394-409.

2. Bhat, R. G., and Browne, G. T. 2007. Genetic diversity in populations of Phytophthora citricola associated with horticultural crops in California. Plant Dis. 91:1556-1563.

3. Bhat, R. G., Colowit, P. M., Tai, T. H., Aradhya, M. K., and Browne, G. T. 2006. Genetic and pathogenic variation in Phytophthora cactorum affecting fruit and nut crops in California. Plant Dis. 90:161-169.

4. Brasier, C., Denman, S., Brown, A., and Webber, J. 2004. Sudden Oak Death (Phytophthora ramorum) discovered on trees in Europe. Mycol. Res. 108:1108-1110.

5. Brasier, C. M., Beales, P. A., Kirk, S. A., Denman, S., and Rose, J. 2005. Phytophthora kernoviae sp. nov., an invasive pathogen causing bleeding stem lesions on forest trees and foliar necrosis of ornamentals in the UK. Mycol. Res. 109:853-859.

6. Browne, G. T., and Viveros, M. A. 1999. Lethal cankers caused by Phytophthora spp. in almond scions: specific etiology and potential inoculum sources. Plant Dis. 83:739-745.

7. Caroselli, N. E. 1953. Bleeding canker disease of hardwoods. Sci. Tree Topics 2:1-6.

8. Day, W. R. 1938. Root-rot of sweet chestnut and beech caused by species of Phytophthora. I. Cause and symptoms of disease: its relation to soil conditions. Forestry 12:101-116.

9. Hansen, E. M., Parke, J. L., and Sutton, W. 2005. Susceptibility of Oregon forest trees and shrubs to Phytophthora ramorum: a comparison of artificial inoculation and natural infection. Plant Dis. 89:63-70.

10. Hong, C., Gallegly, M. E., Browne, G. T., Bhat, R. G., Richardson, P. A., and Kong, P. 2009. The avocado subgroup of Phytophthora citricola constitutes a distinct species, Phytophthora mengei sp. nov. Mycologia 101:833840 .

11. Jung, T. 2009. Beech decline in Central Europe driven by the interaction between Phytophthora infections and climate extremes. For. Pathol. 39:73-94.

12. Jung, T., and Burgess, T. I. 2009. Reevaluation of Phytophthora citricola isolates from multiple woody hosts in Europe and North America reveals a new species, Phytophthora plurivora sp. nov. Persoonia 22:95110.

13. Jung, T., Hudler, G. W., Jensen-Tracy, S. L., Griffiths, H. M., Fleischmann, F., and Osswald, W.-F. 2005. Involvement of Phytophthora species in the decline of European beech in Europe and the USA. Mycologist 19:159-166.

14. Jung, T., Nechwatal, J., Cooke, D.-E.-L., Hartmann, G., Blaschke, M., Osswald, W.-F., Duncan, J.-M., and Delatour, C. 2003. Phy- tophthora pseudosyringae sp. nov., a new species causing root and collar rot of deciduous tree species in Europe. Mycol. Res. 107:772789.

15. Kong, P., Hong, C., Richardson, P.-A., and Gallegly, M.-E. 2003. Single-strandconformation polymorphism of ribosomal DNA for rapid species differentiation in genus Phytophthora. Fungal Genet. Biol. 39:238249.

16. Nelson, A. H. 2009. The etiology and epidemiology of bleeding canker on European beech. Ph.D. thesis. Cornell University, Ithaca, NY.

17. Nelson, A. H., Weiland, J. E., and Hudler, G. W. 2006. New insights into the population diversity of Phytophthora citricola pathogenic on European beech (Fagus sylvatica). (Abstr.) Phytopathology 96:S83.

18. Oudemans, P., Forster, H., and Coffey, M. D. 1994. Evidence for distinct isozyme subgroups within Phytophthora citricola and close relationships with $P$. capsici and $P$. citrophthora. Mycol. Res. 98:189-199.

19. Scott, P. M., Burgess, T. I., Barber, P. A., Shearer, B. L., Stukely, M. J. C., Hardy, G. E. S., and Jung, T. 2009. Phytophthora multivora sp. nov., a new species recovered from declining Eucalyptus, Banksia, Agonis and other plant species in Western Australia. Persoonia 22:1-13.

20. Thomidis, T., Tsipouridis, C., and Karayiannis, I. 2008. Susceptibility of thirty cherry genotypes on Phytophthora cactorum, $P$. citrophthora, P. citricola and $P$. parasitica. J. Phytopathol. 156:446-451.

21. Tooley, P. W., and Kyde, K. L. 2007. Susceptibility of some eastern forest species to Phy tophthora ramorum. Plant Dis. 91:435-438.

22. Vettraino, A. M., Natili, G., Anselmi, N., and Vannini, A. 2001. Recovery and pathogenicity of Phytophthora species associated with a resurgence of ink disease in Castanea sativa in Italy. Plant Pathol. 50:90-96.

23. Weiland, J. E., Nelson, A. H., and Hudler, G. W. 2009. Effects of mefenoxam, phosphonate, and paclobutrazol on in vitro characteristics of Phytopthora cactorum and P. citricola and on canker size of European beech. Plant Dis. 93:741-746.

24. Werres, S. 1995. Influence of the Phytophthora isolate and the seed source on the development of beech (Fagus sylvatica) seedling blight. For. Pathol. 25:381-390.

25. Wilcox, W. F. 1989. Identity, virulence, and isolation frequency of seven Phytophthora spp. causing root rot of raspberry in New York. Phytopathology 79:93-101. 